\title{
NGHIÊN CÚU SỰ THAY ĐỔI SỐ LỰ̛̣NG TIỂU CẦU Ở BỆNH NHÂN TIM MẠCH ĐIỀU TRI TẠI TRUNG TÂM TIM MẠCH - BỆNH VIỆN E TÙ’ THÁNG 1 NĂM 2013 ĐẾN THÁNG 5 NĂM 2016
}

Đào Thị Thanh Nga*, Lê Ngọc Linh*, Lê Ngọc Thành*

\section{TÓM TẮT}

Tìm hiểu sự liên quan giữa tuổi, giới và số lượng tiểu cầu máu ngoại vi ở 7847 bệnh nhân được điều trị tại trung tâm tim mạch. Về giới tính có $45 \%$ nam và $55 \%$ nữ; Về độ tuổi từ 0 đến $4,5-9,10-14,15-17,18$ $34,35-49,50-64,65-74$, và từ 75 tuổi trở lên với số lượng tiểu cầu ở nam lần lượt là $306,1 \pm 106,47 \mathrm{G} / 1$; $267,47 \pm 86,79 \mathrm{G} / 1 ; \quad 255,32 \pm 76,10 \mathrm{G} / 1 ; 222,22 \pm$ 75,09 G/1; 208,23 \pm 57,02 G/1; 210,73 $\pm 61,09 \mathrm{G} / 1$; $211,55 \pm 63,49 \mathrm{G} / 1 ; 206,50 \pm 66,42 \mathrm{G} / 1,205,96 \pm 63,6$ $\mathrm{G} / 1$; ở nữ lần lượt là $305,53 \pm 108,65 \mathrm{G} / 1 ; 257,31 \pm$ $78,85 \mathrm{G} / 1 ; 237,7 \pm 72,71 \mathrm{G} / 1 ; 236,93 \pm 63,21 \mathrm{G} / \mathrm{l}$; $224,97 \pm 57,83 \mathrm{G} / 1 ; 233,88 \pm 62,81 \mathrm{G} / 1 ; 221,93 \pm$ $58,84 \mathrm{G} / 1 ; 222,35 \pm 59,12 \mathrm{G} / 1 ; 215,59 \pm 108,65 \mathrm{G} / 1$. Số lượng tiểu cầu bình thường chiếm tỷ lệ $86,4 \%$, giảm chiếm $9,7 \%$ và tăng chiếm $3,9 \%$. Số lượng tiểu cầu trung bình có xu hướng tăng hơn ở nhóm tuổi nhỏ và giảm dần ở các nhóm tuổi lớn hơn. Số lượng tiểu cầu trung bình ở nữ cao hơn nam ở độ tuổi từ 15-74 tuổi và trên 75 tuổi, và có xu hướng giảm dần sau thời kỳ mãn kinh.

\section{SUMMARY}

Study on platelet count and aging in patients suffer from cardiac diseases and others. To explore the relationship between age, sex and number of peripheral blood platelets in patients being treated at the Heart Center. 7847 patients examined and treated at the Heart Centre. About $45 \%$ sex with men and $55 \%$ women; Of age from 0 to $4,5-9,10-14,15-17$, $18-34,35-49,50-64,65-74$, and over 75 years old and with platelet counts in males respectively there are $306.1 \pm 106.47 \mathrm{G} / 1 ; 267.47 \pm 86.79 \mathrm{G} / \mathrm{l} ; 255.32 \pm$ $76.10 \mathrm{G} / \mathrm{l} ; 222.22 \pm 75.09 \mathrm{G} / \mathrm{l} ; 208.23 \pm 57.02 \mathrm{G} / \mathrm{l}$; $210.73 \pm 61.09 \mathrm{G} / 1 ; 211.55 \pm 63.49 \mathrm{G} / 1 ; 206.50 \pm$ $66.42 \mathrm{G} / 1,205.96 \pm 63.6 \mathrm{G} / \mathrm{l} ;$ and in females respectively $305.53 \pm 108.65 \mathrm{G} / 1 ; 257.31 \pm 78.85 \mathrm{G} / \mathrm{l}$; $237.7 \pm 72.71 \mathrm{G} / 1 ; 236.93 \pm 63.21 \mathrm{G} / \mathrm{l} ; 224.97 \pm 57.83$ $\mathrm{G} / 1 ; 233.88 \pm 62.81 \mathrm{G} / 1 ; 221.93 \pm 58.84 \mathrm{G} / 1 ; 222.35 \pm$ $59.12 \mathrm{G} / \mathrm{l} ; 215.59 \pm 108.65 \mathrm{G} / \mathrm{l}$. Normal platelet counts proportion $86.4 \%$, decreased $9.7 \%$ and increase $3.9 \%$. The average platelet count tends to rise in young age groups and decreased in the older age groups. In 15-74 years old and over 75 years the averages platelet in the women are more than in the men, and tend to decrease after menopause.

\section{I. ĐẠT VẤN ĐỀ}

Tiểu cầu là tế bào nhỏ nhất đường kính 3-4 $\mu \mathrm{m}$, số lượng từ 150-400 G/1, đóng vai trò quan trọng trong cơ chế đông máu, nhất là giai đoạn cầm máu ban đầu. Tiểu cầu được sinh sản từ mẫu tiểu cầu bắt nguồn từ tế bào nguồn dòng tủy, do tế bào gốc tạo máu tạo nên. Mỗi mẫu tiểu cầu có thể tạo được 3000 tiểu cầu. Đời sống tiểu cầu: tiểu cầu có đời sống ngắn, khoảng từ 8-14 ngày.

Số lượng tiểu cầu có thể bị ảnh hưởng trực tiếp do các nguyên nhân bệnh lý mắc phải như tình trạng nhiễm trùng, xuất huyết, huyết khối, khối u, bệnh lý suy gan, suy thận mạn hoặc sử dụng các thuốc chống đông máu... Chức năng tiểu cầu bao gồm chức năng dính và chức năng ngưng tập tiểu cầu. Nhờ có khả năng kết dính, ngưng tập và phóng thích các chất mà tiểu cầu tham gia rất tích cực vào quá trình cầm máu kỳ đầu. Tiểu cầu cũng đóng một vai trò quan trọng trong quá trình đông máu. Đặc biệt đối với bệnh nhân phẫu thuật tim mạch thì các xét nghiệm thăm dò đông máu đóng vai trò quan trọng góp phần thành công cho ca phẫu thuật.

Chính vì vậy, chúng tôi tiến hành nghiên cứu sự thay đổi số lượng tiểu cầu trên bệnh nhân đến khám điều trị tại Trung tâm Tim mạch - bệnh viện E từ tháng 1 năm 2013 đến tháng 5 năm 2016.

\section{II. ĐỐI TƯợNG VÀ PHƯƠNG PHÁP NGHIÊN CÚU}

\section{1. Đối tượng:}

Gồm có 7847 bệnh nhân được khám và điều trị tại Trung tâm Tim mạch, trong đó có 3532 bệnh nhân nam và 4315 bệnh nhân nữ, tuổi từ sơ sinh đến 100 tuổi.

* Trung tâm Tim mạch Bệnh viện E

Người chịu trách nhiệm khoa học: GS.TS. Lê Ngọc Thành

Ngày nhận bài: 18/06/2016 - Ngày Cho Phép Đăng: 18/08/2016

Phản Biện Khoa học: PGS.TS. Đặng Ngoc Hùng GS.TS. Bùi Đức Phú 
Thời gian nghiên cứu từ 1/1/2013 đến 31/5/2016.

2.2. Phương pháp nghiên cứu: mô tả cắt ngang

- Mẫu nghiên cứu gồm các bệnh nhân đến khám và điều trị tại Trung tâm Tim mạch bệnh viện $\mathrm{E}$ với bệnh lý tim mạch - lồng ngực bẩm sinh hoặc mắc phải

- Tiêu chuẩn loại trừ các nguyên nhân trực tiếp gây tăng hoặc giảm số lượng tiểu cầu như có kèm hội chứng cấp tính: nhiễm trùng, xuất huyết, huyết khối; hoặc các trường hợp có khối $u$ ác tính, suy thận mạn, suy gan mạn, hoặc đang điều trị chống đông.

- Tất cả bệnh nhân nghiên cứu đều được làm xét nghiệm tổng phân tích tế bào máu ngoại vi trước khi tiến hành can thiệp hoặc điều trị tại đơn vị Phát máu \& xét nghiệm, Trung tâm Tim mạch - Bệnh viện E.

- Xét nghiệm tổng phân tích tế bào máu ngoại vi được thực hiện trên máy Cell-Dyn 3200 (Abbott, Mỹ) và máy XT 2000i (Sysmex, Nhật).

2.3. Xử lý số liệu: theo phương pháp thống kê y học.

\section{KẾT QUẢ NGHIÊN CÚU}

\section{1. Đặc điểm về tuổi và giới tính:}

Bảng 3.1.1. Đặc điểm về giới tính trong nhóm nghiên cúu

\begin{tabular}{|l|c|c|}
\hline Giới tính & $\mathrm{N}$ & Tỷ lệ \% \\
\hline Nam & 3532 & 45.0 \\
\hline Nữ & 4315 & 55.0 \\
\hline Tổng & 7847 & 100 \\
\hline
\end{tabular}

Nhận xét: nhóm nghiên cứu bao gồm 7847 bệnh nhân trong đó nam chiếm tỷ lệ $45 \%$, nữ chiếm $55 \%$.

Bảng 3.1.2. Đặc điểm về nhóm tuổi

\begin{tabular}{|c|c|c|}
\hline Nhóm tuổi & $\mathrm{N}$ & Tỷ lệ \% \\
\hline 0-4 tuổi & 1444 & 18.4 \\
\hline 5-9 tuổi & 422 & 5.4 \\
\hline 10-14 tuổi & 223 & 2.8 \\
\hline 15-17 tuổi & 59 & 0.8 \\
\hline 18-34 tuổi & 698 & 8.9 \\
\hline 35-49 tuổi & 914 & 11.6 \\
\hline 50-64 tuổi & 2019 & 25.7 \\
\hline 65-74 tuổi & 1208 & 15.4 \\
\hline$\geq 75$ & 860 & 11.0 \\
\hline TỔNG & 7847 & 100.0 \\
\hline
\end{tabular}

Nhận xét: nhóm tuổi có số lượng nhiều nhất là từ 50 đến 64 tuổi chiếm $25,7 \%$, tiếp theo là nhóm dưới 4 tuổi chiếm $18,4 \%$; từ 65 đến 74 tuổi chiếm $15,4 \%$; từ 35 đến 49 tuổi chiếm $11,6 \%$; í nhất là nhóm từ 15 đến 17 tuổi chiếm $0,8 \%$.

\section{2. Đặc điểm về thể bệnh:}

Bảng 3.2.1 Đặc điểm về thể bệnh trong nhóm nghiên cúu

\begin{tabular}{|l|c|c|}
\hline \multicolumn{1}{|c|}{ Thể bệnh } & $\mathrm{N}=7847$ & Tỷ lệ \% \\
\hline Bệnh tim bẩm sinh & 2491 & 31.7 \\
\hline Bệnh lý van tim & 1342 & 17.1 \\
\hline Bệnh lý mạch máu & 2841 & 36.2 \\
\hline $\begin{array}{l}\text { Bệnh lý rối loạn dẫn } \\
\text { truyền }\end{array}$ & 314 & 4.0 \\
\hline \begin{tabular}{l} 
Bệnh cơ tim \\
\hline $\begin{array}{l}\text { Bệnh lý trung thất và } \\
\text { lồng ngực }\end{array}$
\end{tabular} & 58 & 145 \\
\hline Các bệnh khác & 656 & 8.4 \\
\hline
\end{tabular}

Nhận xét: tỷ lệ cao nhất là bệnh lý mạch máu $36,2 \%$, tiếp theo là bệnh tìm bẩm sinh là $31,7 \%$; bệnh lý van tim chiếm $17,1 \%$, bệnh lý cơ tim chiếm $1,9 \%$ bệnh lý rối loạn dẫn truyền $4 \%$, ít nhất là bệnh lý của trung thất lồng ngực $0,7 \%$, nhóm các bệnh khác chiếm $8,4 \%$.

\subsection{Chỉ số tiểu cầu:}

\section{Bảng 3.3.1. Đặc điểm số lựng tiểu cầu}

\begin{tabular}{|c|c|c|}
\hline Số lượng tiểu cầu & $\mathrm{N}$ & Tỷ lệ \% \\
\hline$<150 \mathrm{G} / 1$ & 758 & 9.7 \\
\hline $150-350 \mathrm{G} / 1$ & 6783 & 86.4 \\
\hline$>400 \mathrm{G} / 1$ & 306 & 3.9 \\
\hline Tổng & 7847 & 100.0 \\
\hline
\end{tabular}

Nhận xét: số lượng tiểu cầu bình thường chiếm tỷ lệ lớn nhất $86,4 \%$, giảm chiếm $9,7 \%$ và tăng chiếm $3,9 \%$ 
Bảng 3.3.2. Thay đổi về số lựng tiểu cầu theo tuổi

\begin{tabular}{|c|c|c|c|c|c|c|}
\hline \multirow{2}{*}{ Nhóm tuổi } & \multicolumn{3}{|c|}{ Nam } & \multicolumn{3}{c|}{ Nữ } \\
\cline { 2 - 7 } & $\mathrm{N}$ & $\mathrm{x}^{-}$ & $\mathrm{SD}$ & $\mathrm{N}$ & $\mathrm{x}^{-}$ & SD \\
\hline $0-4$ tuổi & 777 & 306.10 & 106.47 & 667 & 305.53 & 108.65 \\
\hline $5-9$ tuổi & 219 & 267.47 & 86.79 & 203 & 257.31 & 78.85 \\
\hline $10-14$ tuổi & 118 & 255.32 & 76.10 & 105 & 237.70 & 72.71 \\
\hline $15-17$ tuổi & 29 & 222.22 & 75.09 & 30 & 236.93 & 63.21 \\
\hline $18-34$ tuổi & 294 & 208.23 & 57.02 & 404 & 224.97 & 57.83 \\
\hline $35-49$ tuổi & 343 & 210.73 & 61.09 & 571 & 233.88 & 62.81 \\
\hline $50-64$ tuổi & 822 & 211.55 & 63.49 & 1197 & 221.93 & 58.84 \\
\hline $65-74$ tuổi & 534 & 206.50 & 66.42 & 674 & 222.35 & 59.12 \\
\hline$\geq 75$ & 396 & 205.96 & 63.60 & 464 & 215.59 & 108.65 \\
\hline
\end{tabular}

Nhận xét:

Số lượng tiểu cầu trong nhóm nghiên cứu cao hơn ở nhóm tuổi nhỏ và giảm dần ở các nhóm tuổi lớn hơn. Ở nhóm nam dưới 14 tuổi số lượng tiểu cầu có $\mathrm{xu}$ hướng cao hơn nữ, nhưng từ 15 tuổi trở lên số lượng tiểu cầu ở nữ cao hơn nam. Cụ thể như sau:

Nhóm từ $0-4$ tuổi có số lượng tiểu cầu cao nhất. Ở nam là 306,1 $\pm 106,47 \mathrm{G} / 1$ cao hơn ở nữ $(305,53 \pm$ 108,65 G/1) nhưng không có sự khác biệt.

Nhóm 5 - 9 tuổi số lượng tiểu cầu giảm hơn. Tiểu cầu ở nam là $267,47 \pm 86,79 \mathrm{G} / 1$ ở nữ là $257,31 \pm$ $78,85 \mathrm{G} / 1$. Số lượng tiểu cầu ở nam cao hơn nữ.

Nhóm 10 - 14 tuổi số lượng tiểu cầu giảm hơn nữa. Tiểu cầu ở nam là $255,32 \pm 76,10 \mathrm{G} / 1$ ở nữ là $237,7 \pm 72,71 \mathrm{G} / 1$. Số lượng tiểu cầu ở nam cũng cao hơn nữ.

Nhóm 15 - 17 tuổi số lượng tiểu cầu ở nam là $222,22 \pm 75,09 \mathrm{G} / 1$ ở nữ là 236,93 $\pm 63,21 \mathrm{G} / 1$. Số lượng tiểu cầu của nam ở nhóm này thấp hơn nữ.

Nhóm 18 - 34 tuổi số lượng tiểu cầu ở nam là $208,23 \pm 57,02 \mathrm{G} / 1$, ở nữ là 224,97 $\pm 57,83 \mathrm{G} / 1$. Số lượng tiểu cầu của nam thấp hơn nữ.
Nhóm 35 - 49 tuổi số lượng tiểu cầu ở nam là $210,73 \pm 61,09 \mathrm{G} / 1$, ở nữ là $233,88 \pm 62,81 \mathrm{G} / 1$. Số lượng tiểu cầu của nam thấp hơn nữ.

Nhóm 50 - 64 tuổi số lượng tiểu cầu ở nam là $211,55 \pm 63,49 \mathrm{G} / 1$, ở nữ là $221,93 \pm 58,84 \mathrm{G} / 1$. Số lượng tiểu cầu của nam thấp hơn nữ.

Nhóm 65 - 74 tuổi số lượng tiểu cầu ở nam là $206,50 \pm 66,42 \mathrm{G} / 1$, ở nữ là $222,35 \pm 59,12 \mathrm{G} / 1$. Số lượng tiểu cầu của nam thấp hơn nữ.

Nhóm từ 75 tuổi trở lên có số lượng tiểu cầu thấp nhất: ở nam là 205,96 $\pm 63,6 \mathrm{G} / 1$, ở nữ là 215,59 \pm $108,65 \mathrm{G} / 1$. Số lượng tiểu cầu của nam thấp hơn nữ.

\section{BÀN LUẬN}

Trong nghiên cứu của chúng tôi với 7847 bệnh nhân tuổi từ sơ sinh đến 100 tuổi. Về giới tính nam chiếm $45 \%$ nữ chiếm $55 \%$. Trong đó nhóm bệnh nhân từ 50-64 tuổi chiếm tỷ lệ cao nhất $25,7 \%$, nhóm từ 0 đến 4 tuổi chiếm tỷ lệ $18,4 \%$, nhóm từ 65 đến 74 tuổi chiếm $15,4 \%$; từ 35 đến 49 tuổi chiếm $11,6 \%$; ít nhất là nhóm từ 15 đến 17 tuổi chiếm $0,8 \%$. Bệnh nhân nhỏ tuổi nhất là 5 ngày tuổi bệnh nhân cao tuổi nhất là 100 
tuổi. Như vậy, bệnh nhân đến khám và điều trị tại Trung tâm tim mạch đa dạng về tuổi và giới.

Đặc điểm về thể bệnh trong nhóm nghiên cứu, bệnh lý mạch máu chiếm tỷ lệ cao nhất là $36,2 \%$, tiếp theo là bệnh lý tim bẩm sinh là $31,7 \%$; bệnh lý van tim chiếm $17,1 \%$, bệnh lý cơ tim chiếm 1,9\%, bệnh lý rối loạn dẫn truyền $4 \%$, ít nhất là bệnh lý trung thất và lồng ngực $0,7 \%$, nhóm các bệnh khác chiếm $8,4 \%$.

Nhóm bệnh lý mạch máu bao gồm bệnh lý hệ động mạch như phình động mạch chủ ngực, chủ bụng, hẹp động mạch cảnh, mạch vành, các cơn đau thắt ngực, cao huyết áp, bệnh lý hệ tĩnh mạch. Nhóm bệnh lý tim bẩm sinh gồm có thông liên thất, thông liên nhĩ, còn ống động mạch, Fallot và các loại tim bẩm sinh phức tạp.

Đặc điểm về số lượng tiểu cầu:

Bình thường số lượng tiểu cầu nói chung ít thay đổi. Trẻ sơ sinh số lượng tiểu cầu từ $100-400 \mathrm{G} / \mathrm{L}$, ngoài tuổi sơ sinh số lượng tiểu cầu từ 150 - $400 \mathrm{G} / \mathrm{L}$.

Trong nghiên cứu của chúng tôi phần lớn bệnh nhân có số lượng tiểu cầu bình thường chiếm tỷ lệ lớn nhất $86,4 \%$, giảm chiếm $9,7 \%$ và tăng chiếm $3,9 \%$. (Nguyễn Quang Tùng tỷ lệ bệnh nhân có số lượng tiểu cầu bình thường là $82,5 \%$ ). Theo Biino $\mathrm{G}$ tỷ lệ những người khỏe mạnh ở độ tuổi dưới 18 với số lượng tiểu cầu trên $400 \times 10^{\wedge} 9 / \mathrm{L}$ là $11 \%$ và hơn $10 \%$ trên 60 tuổi có số lượng tiểu cầu dưới 150 $\times 10^{\wedge} 9 /$ L là $4,5 \%$.

Số lượng tiểu cầu có xu hướng tăng hơn ở nhóm tuổi nhỏ và giảm dần ở các nhóm tuổi lớn hơn. Ở nhóm nam dưới 14 tuổi số lượng tiểu cầu có xu hướng cao hơn nữ, nhưng từ 15 tuổi trở lên số lượng tiểu cầu ở nữ cao hơn nam.

Nhóm từ $0-4$ tuổi có số lượng tiểu cầu cao nhất. Ở nam là 306,1 $\pm 106,47 \mathrm{G} / 1$ cao hơn ở nữ $(305,53 \pm$ 108,65 G/1) nhưng không có sự khác biệt.

Nhóm 5 - 9 tuổi số lượng tiểu cầu giảm hơn. Tiểu cầu ở nam là $267,47 \pm 86,79 \mathrm{G} / 1$ ở nữ là $257,31 \pm$ 78,85 G/1. Số lượng tiểu cầu ở nam cao hơn nữ.

Nhóm 10 - 14 tuổi số lượng tiểu cầu giảm hơn nữa. Tiểu cầu ở nam là $255,32 \pm 76,10 \mathrm{G} / 1$ ở nữ là
$237,7 \pm 72,71 \mathrm{G} / 1$. Số lượng tiểu cầu ở nam cũng cao hơn nữ.

Nhóm 15 - 17 tuổi số lượng tiểu cầu ở nam là $222,22 \pm 75,09 \mathrm{G} / 1$ ở nữ là $236,93 \pm 63,21 \mathrm{G} / 1$. Số lượng tiểu cầu của nam ở nhóm này thấp hơn nữ.

Nhóm 18 - 34 tuổi số lượng tiểu cầu ở nam là $208,23 \pm 57,02 \mathrm{G} / 1$, ở nữ là $224,97 \pm 57,83 \mathrm{G} / 1$. Số lượng tiểu cầu của nam thấp hơn nữ.

Nhóm 35 - 49 tuổi số lượng tiểu cầu ở nam là $210,73 \pm 61,09 \mathrm{G} / 1$, ở nữ là $233,88 \pm 62,81 \mathrm{G} / 1$. Số lượng tiểu cầu của nam thấp hơn nữ.

Nhóm 50 - 64 tuổi số lượng tiểu cầu ở nam là $211,55 \pm 63,49 \mathrm{G} / 1$, ở nữ là $221,93 \pm 58,84 \mathrm{G} / 1$. Số lượng tiểu cầu của nam thấp hơn nữ.

Nhóm 65 - 74 tuổi số lượng tiểu cầu ở nam là $206,50 \pm 66,42 \mathrm{G} / 1$, ở nữ là $222,35 \pm 59,12$ G/l. Số lượng tiểu cầu của nam thấp hơn nữ.

Nhóm từ 75 tuổi trở lên có số lượng tiểu cầu thấp nhất: ở nam là 205,96 $\pm 63,6 \mathrm{G} / 1$, ở nữ là 219,59 \pm $108,65 \mathrm{G} / 1$. Số lượng tiểu cầu của nam thấp hơn nữ.

Số lượng tiểu cầu trung bình của nữ thấp hơn nam giới trong các nhóm tuổi từ 0 đến 14 , sự khác biệt này không có ý nghĩa thống kê. Nhưng số lượng tiểu cầu trung bình ở nữ lại cao hơn nam ở độ tuổi từ 15-64 và trên 64 tuổi, mặc dù sự khác biệt là rất nhỏ, và có xu hướng giảm dần sau thời kỳ mãn kinh.

Như vậy, số lượng tiểu cầu giảm theo tuổi và phụ nữ có tiểu cầu cao hơn nam sau tuổi dậy thì. Sau tuổi dậy thì có sự khác biệt hormon giữa nam và nữ, hiện tượng kinh nguyệt và sinh sản liên quan đến giảm nồng độ sắt huyết thanh. Có lẽ việc giảm chất sắt trong cơ thể phụ nữ, kinh nguyệt và mang thai đã kích thích sản xuất tiểu cầu nhiều hơn.

Nghiên cứu của chúng tôi phù hợp với nghiên cứu của Greham SS (năm 1987), Biino G (năm 2011) và Buckley MF (năm 2000).

So sánh số lượng tiểu cầu có sự khác biệt khoảng $100 \mathrm{G} / 1$ giữa trẻ em từ $0-4$ và người cao tuổi trên 74 tuổi. Liên quan đến các cơ chế giảm tiểu cầu ở tuổi già có thể do giảm dự trữ tế bào gốc tạo máu. Như vậy, tuổi tác là một yếu tố quyết định số lượng tiểu cầu. Nghiên cứu của chúng tôi phù hợp với nghiên 
cứu của Greham SS (năm 1987), Segal JB (năm 2006) và Satimone I (năm 2011).

\section{KẾT LUẬN}

Qua khảo sát trên 7847 bệnh nhân được khám và điều trị tại Trung tâm tim mạch - Bệnh viện $\mathrm{E}$, chúng tôi rút ra một số kết luận như sau:

- Về giới tính có $45 \%$ nam và $55 \%$ nữ;

- Về độ tuổi có $18,4 \%$ từ 0 đến 4 tuổi; $5,4 \%$ từ 5 đến 9 tuổi; $2,8 \%$ từ $10-14$ tuổi; $0,8 \%$ từ 15 đến 17 ; $8,9 \%$ từ $18-34$ tuổi; $11,6 \%$ từ $35-49$ tuổi; $25,7 \%$ từ 50 64 tuổi; $15,4 \%$ từ $65-74$ tuổi; $11 \%$ từ trên 75 tuổi.

- Số lượng tiểu cầu bình thường chiếm tỷ lệ $86,4 \%$, số lượng tiểu cầu giảm chiếm $9,7 \%$ và số lượng tiểu cầu tăng chiếm 3,9\%.

- Số lượng tiểu cầu trung bình của nam cao hơn nữ ở tuổi trước dậy thì. Số lượng tiểu cầu có xu hướng tăng hơn ở nhóm tuổi nhỏ và giảm dần ở các nhóm tuổi lớn hơn. Số lượng tiểu cầu trung bình ở nữ cao hơn nam ở độ tuổi từ 15-74 tuổi và trên 75 tuổi, và có xu hướng giảm dần sau thời kỳ mãn kinh.

\section{TÀI LIỆU THAM KHẢO}

- Nguyễn Công Khanh (2008) "Huyết học lâm sàng nhi khoa" NXB Y học: 24-45.

- Nguyễn Quang Tùng, Trần Mai Hồng (2012) "nghiên cứu sự thay đổi một số chỉ số huyết học ở bệnh nhân tim bẩm sinh" Tạp chí Y học Việt Nam, tập 396: 226-230.

- Trường Đại học Y Hà Nội, Bộ môn Nhi (2009)“Bài giảng nhi khoa” tập 2 NXB Y học.

- Trường Đại học Y Hà Nội, Bộ môn Huyết họcTruyền máu "Bài giảng Huyết học Truyền máu" NXH Y học 2004.

- Beguin Y. Erythropoietin and platelet production. Haematologica1999; 84(6): 541-7

- Biino G, Gasparini P, D’Adamo P, Ciullo M, Nutile T, Toniolo D, et al. Influence of age, sex and ethnicity on platelet count in five Italian geographic isolates: mild thrombocytopenia may be physiological. Br J Haematol 2012; 157(3):384-7

- Biino G, Santimone I, Minelli C, Sorice R, Frongia $\mathrm{B}$, Traglia $\mathrm{M}$, et al. Age- and sex-related variations in platelet count in Italy: a proposal of reference ranges based on 40987 subjects' data. PLoS One 2013;8(1):e54289.

- Buckley MF, James JW, Brown DE, Whyte GS, Dean MG, Chesterman CN, et al. A novel approach to the assessment of variations in the human platelet count. Thromb Haemost2000;83(3):480-4

- Kadikoylu G, Yavasoglu I, Bolaman Z, Senturk T. Platelet parameters in women with iron deficiency anemia. J Natl Med Assoc2006;98(3): 398-402

- Nagata Y, Yoshikawa J, Hashimoto A, Yamamoto M, Payne AH, Todokoro K. Proplatelet formation of megakaryocytes is triggered by autocrine-synthesized estradiol. Genes Dev2003;17(23):2864-9

- Santimone I, Di Castelnuovo A, De Curtis A, Spinelli M, Cugino D, Gianfagna F, et al. White blood cell count, sex and age are major determinants of heterogeneity of platelet indices in an adult general population: results from the MOLI-SANI project. Haematologica2011;96(8):1180-8

- Segal JB, Moliterno AR. Platelet counts differ by sex, ethnicity, and age in the United States. Ann Epidemiol 2006;16(2):123-30

- Sloan AW. The normal platelet count in men. J Clin Path1951;4(1):37-46

- $\quad$ Stasi R, Amadori S, Osborn J, Newland AC, Provan D. Long-term outcome of otherwise healthy individuals with incidentally discovered borderline thrombocytopenia. PLoS Med 2006;3(3):e24.

- Stevens RF, Alexander MK. A sex difference in the platelet count.Br J Haematol 1977;37(2):295-300 